\title{
The 'Healthy Passport' intervention with older people in an English urban environment: effects of incentives and peer-group organisers in promoting healthy living
}

\author{
CAROL A. HOLLAND*, PAULINE EVERITT $\dagger$, \\ ANGELA JOHNSON** and REENA DEVI*
}

\begin{abstract}
This paper reports the evaluation of the effectiveness of incentives (viz. points and prizes) and of peer-group organisers ('older people's champions') in the outcomes of a health-improvement programme for people aged $50+$ years in a multi-ethnic district of the West Midlands, England. Health promotion activities were provided, and adherence, outcome variables and barriers to adherence were assessed over six months, using a 'passport' format. Those aged in the fifties and of Asian origin were under represented, but people of Afro-Caribbean origin were well represented and proportionately most likely to stay in the project. Those of greater age and with more illness were most likely to drop out. There were significant improvements in exercise, diet and the uptake of influenza vaccines and eyesight tests, but slighter improvements in wellbeing. Positive outcomes related to the incentives and to liking the format. The number of reported barriers was associated with lower involvement and lack of change, as was finding activities too difficult, the level of understanding, and transport and mobility problems, but when these were controlled, age did not predict involvement. Enjoying the scheme was related to positive changes, and this was associated with support from the older people's champions.
\end{abstract}

$\boldsymbol{K E Y} \boldsymbol{W} O \boldsymbol{R} D S$ - health promotion, intervention, older adults, incentives, peergroup organisers.

\section{Health promotion for older people}

This paper reports an evaluation of a health intervention scheme, 'The Healthy Passport', which targeted older residents in Sandwell, a relatively

* School of Life and Health Sciences, Aston University, Birmingham, West Midlands, UK.

$\dagger$ Agewell, West Bromwich, West Midlands, UK.

** Sandwell Primary Care Trust, West Bromwich, West Midlands, UK. 
deprived and multi-ethnic area of the West Midlands conurbation of England. Although a specific local intervention, the challenges that were faced are common aims for older-adult health improvement programmes, particularly those in similar relatively deprived areas in developed countries ( $c f$. Maddox 1985). Distinctive features of the Healthy Passport scheme were its use of incentives to take part and to encourage long term adherence (a points scheme that rewarded participation and that translated into prizes), and the role of peer-group facilitators who recruited the participants, explained the scheme, and provided continuing support.

\section{The role of incentives}

Whether incentives improve adherence to health interventions has been much discussed, but no consensus has been reached, partly because evaluations find it difficult to disentangle their influence from the multiple components of most programmes. The review of exercise interventions by Akke, Laurant and Wensing (2002) suggested that incentives had little influence, but other studies have suggested that in some circumstances they have an effect. For example, Pereira et al. (1998) found that an intervention aimed at increasing walking amongst post-menopausal women and that used reinforcements such as birthday cards, telephone reminders and rewards, showed significantly higher activity among the participants than in controls even after io years, although the extent to which the success was attributable to the reward component could not be established.

Evidence from other rehabilitation fields has provided strong support for the use of rewards in encouraging adherence, notably in the treatment of drug addiction (e.g. Kellogg et al. 2005). A review of incentive schemes with young adults suggested that schemes with a limited number of components (preferably one or two), where a simple behaviour is required, were effective in encouraging positive health behaviours (Kavanagh et al. 2006). This study specifically referred to the positive effect of incentives on smoking reduction and immunisation take-up. Another review of II incentive schemes with a wider range of patients (although not older patients specifically) by Giuffrida and Torgerson (1997) found that io showed a positive effect of financial incentives on patient compliance. Some evidence supports the use of points as well as intermittent prizes as a reinforcement system, with small rewards being given for the desired behaviour (e.g. a point is given for attending an exercise class), and larger rewards to mark the attainment of specific goals. It has been suggested by work in the drug rehabilitation field that such a system particularly motivates people who would normally be the least responsive and are most in need of help (Petry and Bohn 2003). This design was adopted for the 
reported evaluation. The most suitable forms of rewards and their administration are difficult to determine for either entire age groups or individuals even with careful piloting (see Kavanagh et al. 2006). Indeed some are offered that no one wants. The individual personal importance of the incentives can influence the outcomes and this relationship needs to be assessed, rather than assessing the overall effect of the simple presence or absence of reward.

\section{Barriers to adherence}

Anderson et al. (2000) outlined the factors that need to be considered in predicting adherence to health interventions for older adults. Barriers to adherence include initial health status, mobility restrictions, social activity limitations and isolation. The Healthy Passport project assessed a number of these potential barriers, and additionally included self-rated mood/ depression indicators, all of which can be used to ascertain predictors of successful uptake, change and drop-out. It is well known that those who stay in long-term interventions or studies differ significantly from those who drop out, which is known as selective attrition (Rabbitt et al. 2004). This influences the population likely to benefit most from health-related behaviour change interventions. It is unfortunately the case that those most in need of intervention are usually those most likely to drop out - the less healthy, the more mobility restricted, the more visually impaired, the eldest, and those who have less understanding of the usual forms of information communication (for example, those with limited educational background or with language difficulties). Some intervention programmes have concluded that targeting the 'younger old', or the newly retired, healthier, more active older population is most effective even if at the time they seem in little need of such interventions. Making changes to lifestyle and attitudes when aged in the late fifties or early sixties can have significant long-term benefits that are far more effective than targeting those aged in the eighties or older (e.g. Deery, Day and Fildes 200o). The influence of age within the over-fifties group on effectiveness of the intervention will be examined here.

\section{The role of peer-group support}

Anderson et al. (2000) suggested that the level of social support influences the level of compliance to a health intervention. Peer-group organisers, mentors or educators are widely employed in connection with health and involvement promotion amongst older adults in many countries, as in the United Kingdom, (e.g. Age Concern 2007), The Netherlands (e.g. Kocken and Voorham 1998), and Australia (e.g. Deery, Day and Fildes 2000), 
although direct evaluations of their effectiveness are rare. Nevertheless, the consensus is that the presence of peer-supporters improves the reception, retention and reach of health education (e.g. Lynde I992). One clear example is the cited Deery et al. evaluation of a falls prevention intervention with older people. They demonstrated that peer-group educators had a significant effect on attitudes to falls and prevention behaviour, and that the participants retained knowledge about prevention more than a control group, although the results on the actual reduction in falls were disappointing. Research has more specifically suggested that 'buddy systems', or peer-group support, have an important influence on adherence to exercise programmes among older adults (Akke, Laurant and Wensing 2002). The fact that the majority of such studies are randomised control trials with multiple components means that differences between groups are not clearly attributable to any one factor. This study, however, will examine the influence of the participants' self-rating of received support from the champions on adherence and outcomes by analysing the relationship rather than by between-group comparison.

\section{Sandwell and the Healthy Passport scheme}

Sandwell is a metropolitan district (or administrative borough) of the West Midlands urban area of England. ${ }^{1}$ The district is one of several former industrial and mining areas in the United Kingdom (UK) with lower than national average life expectancy. It was designated a 'Health Action Zone' during I998-200I, and through from that period has received many and varied programmes to improve the health and quality of life of its residents, many with an emphasis on community-focused healthcare. In 2004 Sandwell and several similar areas were designated as the 'Spearhead Group' for new health promotion programmes, with a target of reducing the life expectancy gap by io per cent by $2010 .{ }^{2}$ In 2005 , however, a review of the Spearhead programme areas found that the rate of progress was too slow in some of the areas, including Sandwell (Department of Health (DOH) 2006: Figure 8). It is now a particular focus for initiatives as part of the National Health Service (NHS) 'Choosing Health Agenda' that stemmed from the public health White Paper Choosing Health (DOH 2004). The 'Healthy Passport' project featured in this paper is one such initiative that seeks to improve the health of residents aged $5^{0}$ or more years, by enabling them to enjoy a happier and healthier lifestyle in old age.

The programme comprises several interventions that aim to improve the fitness and health of older people. The fact that the 'Healthy Passport' 
project took place in an area that has received heightened attention and funding in recent years should be borne in mind. Several of the tasks set or activities made available to those taking part in the project were already well established in the community, including the activities of peer-group supporters, known locally as older people's champions. In addition, the coordinating bodies, Agewell ${ }^{3}$ and the local NHS Primary Care Trust (PCT), have a good reputation for services to older adults, which gave credibility to the scheme.

The 'Healthy Passport' scheme was run in three different areas of the borough and co-ordinated by Agewell. Each area has a boroughappointed older people's champion, who was asked to recruit and support the participants as part of their wider role. The choice of area in which to run the project was based on which areas had a champion. The champions were all of the same age range as the intended participants in the Healthy Passport scheme, and some became participants themselves. The champions recruited participants from amongst their friends and acquaintances, from local clubs and organisations for older people, and from a 'forum' of older people that is involved in services for their age group. There were press releases in the local newspaper, posters were displayed at community venues, and information was sent to general practitioner (GP) surgeries, to borough officers, public housing officers, older people's group leaders, community nurses, and to staff involved in each of the interventions.

\section{The intervention tasks}

The Healthy Passport scheme offered various activities, or tasks, and the participants received points when they were completed. Each participant could choose which tasks to take part in. Each was given a booklet (the 'Passport') that detailed the tasks and how to earn points. It has pages on which the activity providers confirm that the participant has taken part and therefore earned points. ${ }^{4}$ Once participants had achieved I 5 points, they received a pair of non-slip slippers, a Io per cent discount pass for activities at a local leisure centre or a meal at the local cafe. At $3^{0}$ points, they received a $£ 20$ gift voucher. ${ }^{5}$ The tasks were as follows :

Extend class - gentle exercises designed to improve mental and physical health. Home-accident assessment - from NHS Home Accident Prevention Services (HAPS). Stop smoking - participants were required to arrange an appointment with a 'Stop Smoking Service Advisor', and earned more points by staying tobacco-free for four weeks.

Healthy-eating exercise - participants attended food interest groups, which tasted healthier options and discussed healthy-eating habits. 
Health assessments - participants attended a 45-minute health assessment and received an individual exercise programme. A re-assessment was carried out after io weeks to ensure the programme was improving their health.

Vaccinations - influenza and pneumonia vaccinations were promoted. These were carried out by the participant's own health provider to ensure appropriateness. The vaccinations are available under the NHS to all those aged 65 or more years and to younger people with certain health problems (e.g. asthma, history of pneumonia). The vaccinations were therefore not freely available to some of the younger participants.

Adult cycle training - one-to-one professional cycle training for all levels of ability.

Family cycle-rides - a monthly bike-ride lasting two hours.

Health walk-45-6o minutes walks with qualified 'health walk leaders'.

Green gym - nature conservation activities, e.g. tree planting, creating wildflower gardens.

Energy efficiency home check - designed to help people keep homes warm and reduce energy bills.

\section{The evaluation study}

The analysis reported in this paper concentrated on the features of the scheme that are generalisable to health promotion programmes for older people in any country or setting, and the factors that prevent or hinder full participation and the resulting benefits. The aim of the evaluation was to focus on the factors that promoted adherence, involvement and changes in health-related measures, after taking into account barriers to involvement. The key features of particular interest were the roles of incentives and of the older people's champions. The specific questions examined in order to fulfil the aims were as follows:

I. Who took part? Were participants representative of their community?

2. Who carried on? Were there demographic and health-status differences between those who carried on and those who did not?

3. What predicted duration and extent of involvement (i.e. how many points they achieved)? This was examined by personal predictors (age, gender, health-status measures), and by the importance of the incentives, support received from the peer-group organisers and reception of the programme (e.g. ease of use of the Passport).

4. Did people change as a result of the Passport?

(a) Did people make positive health-related changes - e.g. change diet, take-up vaccinations or new exercise activities?

(b) Did people change in basic measures of happiness, feelings of control over health, and feeling that their health problems restricted their activities?

5. What predicted change? 


\section{Methods}

The evaluation had a prospective design with three waves of data collection. Participants were invited to complete the monitoring questionnaire at registration with the 'Healthy Passport', on achieving I5 points and at 30 points (that is, they were given a follow-up form each time they claimed their prizes).

\section{The research instruments}

The monitoring questionnaire had items on the participant's current illnesses, self-rating of health, effect of health on everyday activities, beliefs about health as a matter of luck (i.e. feelings of control over health), and general happiness. There were also questions about everyday health-related behaviours (e.g. diet, smoking and exercise), routine check-ups at opticians, and take-up of vaccinations. The evaluation questionnaire was sent to people when they registered, and could be completed and returned at any stage (although most did so towards the end). It sought the participant's views on the format and design of the Health Passport and whether they found it easy or difficult to understand. If the participant had not managed to achieve the maximum 30 points, they were asked what barriers they had experienced. Feelings regarding the personal importance of the incentives were queried, and the participants were asked if they felt they had changed as a result of the scheme, and specifically what changes they had experienced or made. They were also asked whether they would take part again. $^{6}$

\section{Results}

\section{Recruitment and the participants}

The evaluation questionnaire collected information about the recruitment pathway. The most productive was through local older people's groups and clubs $(74 \%)$, followed by personal introductions by a champion ( $14 \%)$, being told about it by a friend $(6 \%)$, and newspaper advertisements (I \%). Altogether 186 participants completed the initial monitoring questionnaire at registration. Their average age was $7 \mathrm{r} .3$ years (standard deviation (SD) $8.5)$, and of the 186 participants, $154(83 \%)$ were female and 30 were male. ${ }^{7}$ One-third (6I or $32 \%$ ) of the registrants returned a second monitoring questionnaire when they acquired I5 points, and 34 of these (onesixth of the original registrants, or $17 \%$ ) carried on to achieve 30 points and return the final monitoring questionnaire. In addition, 7I $(38 \%)$ of the registrants returned an evaluation questionnaire, and of these 70 per cent 
T A B L E I. Age structure of those aged 50 or more years in Sandwell, West Midlands, UK, $200 \mathrm{I}$ census population and registered participants in Healthy Passport

\begin{tabular}{|c|c|c|c|c|c|c|c|}
\hline \multirow{3}{*}{$\begin{array}{l}\text { Age } \\
\text { group } \\
\text { (years) }\end{array}$} & \multirow{3}{*}{$\begin{array}{c}\text { Sandwell MB: } \\
\text { 200I census } \\
\%\end{array}$} & \multicolumn{6}{|c|}{ Participants in Healthy Passport } \\
\hline & & \multicolumn{2}{|c|}{ At registration } & \multicolumn{2}{|c|}{ With I5 points } & \multicolumn{2}{|c|}{ With 30 points } \\
\hline & & $\%$ & Number & $\%$ & Number & $\%$ & Number \\
\hline $5^{0-54}$ & 25 & I & 2 & $\mathrm{o}$ & o & $\mathrm{o}$ & 0 \\
\hline $55-59$ & I4 & 6 & I2 & 3 & 2 & I2 & 4 \\
\hline $6 o-64$ & I4 & 17 & $3 \mathrm{I}$ & I7 & IO & 24 & 8 \\
\hline $65^{-69}$ & I4 & 17 & $3^{\mathrm{I}}$ & $2 \mathrm{I}$ & I3 & $\mathrm{I} 2$ & 4 \\
\hline $70^{-74}$ & II & I8 & 34 & $2 \mathrm{I}$ & I3 & 29 & Io \\
\hline $75^{-79}$ & II & $2 \mathrm{I}$ & 39 & 26 & I6 & 24 & 8 \\
\hline $80-84$ & 6 & II & $2 \mathrm{I}$ & IO & 6 & 0 & o \\
\hline $85^{-89}$ & 3 & 5 & IO & 2 & I & $\mathrm{o}$ & o \\
\hline $90+$ & 3 & 0.5 & I & $\mathrm{o}$ & 0 & 0 & o \\
\hline Missing & & & 5 & & o & & o \\
\hline Total & & & I86 & & $6 \mathrm{I}$ & & 34 \\
\hline
\end{tabular}

Note: The population aged $50+$ years was $3^{6}$ per cent of the all-age population in 200 I.

were women (average age 67.0 years). Given that only i7 per cent completed a monitoring form at 30 points, clearly many who did not reach this target completed an evaluation form.

Age and ethnicity of those who registered and who continued

The age distribution of the participants, all of whom were aged 5o or more years, was compared with that enumerated by the 200I population census for Sandwell (Table I). Compared to the borough's population, few aged in the fifties took part. The modal five-year age-group of the participants was 75-79 years, and the great majority were between 60 and 84 years. Table 2 compares the ethnic groups of the participants with the borough statistics. The majority of people living in Sandwell are white, although some neighbourhoods have a high proportion of ethnic minority residents. Among the borough's minority ethnic groups, the percentages aged over 50 years are lower than that for the British white group: only I7.4 per cent of Indians in the area are over 50 years old, 26.2 per cent of Caribbean people and 9.7 per cent of Black African people, compared with 37 per cent of the white population (Research Sandwell, 2007). These differences are reflected in the intervention sample characteristics. The AfroCaribbean population was well represented, but those of Indian origin under represented. There were no registrants of Pakistani, Bangladeshi or Chinese origin, although I0.3, 8.5 and 22.7 per cent of their respective populations were aged 50 or more years. 
T A в L E 2. Percentage of Sandwell's population aged 50 or more years by ethnic group, 200 I census and participants in the Healthy Passport scheme

\begin{tabular}{|c|c|c|c|c|c|c|c|}
\hline \multirow[b]{3}{*}{ Ethnic group } & \multirow{3}{*}{$\begin{array}{c}\text { Sandwell MB: } \\
\text { 200I census } \\
\%\end{array}$} & \multicolumn{6}{|c|}{ Healthy Passport participants } \\
\hline & & \multicolumn{2}{|c|}{ At registration } & \multicolumn{2}{|c|}{ With I5 points } & \multicolumn{2}{|c|}{ With 30 points } \\
\hline & & Number & $\%$ & Number & $\%$ & Number & $\%$ \\
\hline White & 88 & I69 & $9^{\mathrm{I}}$ & 53 & 87 & 30 & 88 \\
\hline Indian & 5 & I & 0.5 & o & o & o & o \\
\hline African-Caribbean & 3 & I3 & 7 & 8 & I3 & 4 & $\mathrm{I} 2$ \\
\hline Missing & - & 2 & I & o & $\mathrm{o}$ & $\mathrm{O}$ & $\mathrm{O}$ \\
\hline Total & & I86 & & 6 I & & 34 & \\
\hline
\end{tabular}

Note: No participants were from six other ethnic groups described by the 200I census, as follows: Pakistani (one per cent of $200 \mathrm{I}$ population in the age group), Bangladeshi (0.4\%), Black Other $(<$ o.I \%), Chinese (o.I \%), Other Asian (0.4\%) and Other $(2.8 \%)$.

The average age of the 6I participants who acquired I5 points was $7 \mathrm{I} .3$ years $(\mathrm{SD}=7.2)$, but the 34 who carried on to 30 points were younger (average age 68.8 years, $\mathrm{SD}=6.0$ ) (Table I). No participants aged 80 or more years or less than 55 years continued to 30 points. There was no significant age difference between those who achieved 15 points and those who did not, but those who carried on to achieve 30 points were significantly younger than the baseline registrants $(t=2.25, p<0.05, \mathrm{~N}=130)$, indicating a consistent, non-random drop out of older participants. Turning to the ethnic groups of those who acquired points, all who carried on to 15 points were either of White British or Afro-Caribbean origin (Table 2). Only 3I per cent of the whites gained I5 points, compared to 6I per cent of the many fewer Afro-Caribbeans. Both ethnic groups lost about $5^{\circ}$ per cent of the participants between ${ }_{5} 5$ and 30 points. The difference in the retention rates of the two groups was statistically significant $\left(\chi^{2}=\mathrm{I} 3.4(\mathrm{df}=\mathrm{I}), p<\right.$ o.OI $)$.

\section{Health and lifestyle profiles}

There were small differences at registration between those who later dropped out and those who continued, generally in expected directions (Table 3). For example, those who dropped out reported more health problems and were slightly less active, but these differences were, with a few exceptions, not large or consistent enough to be statistically significant. Those who dropped out were marginally more likely to report that their physical or emotional problems interfered with social activities $(F=3.68$ (df I, I29), $p=0.06$ ), and significantly more likely to answer 'yes' to the 
T A B L E 3. Question responses of those who dropped out compared to those at 30 points

\begin{tabular}{|c|c|c|c|}
\hline Question or assertion & $\begin{array}{l}\text { Response } \\
\text { categories }\end{array}$ & $\begin{array}{c}\text { Dropped } \\
\text { out } \\
\%\end{array}$ & $\begin{array}{l}30 \text { points } \\
\%\end{array}$ \\
\hline \multirow{2}{*}{$\begin{array}{l}\text { I. Do you have a long standing illness that } \\
\text { affects your day to day activities? }\end{array}$} & Yes & 62 & $3^{8}$ \\
\hline & No & 39 & 53 \\
\hline \multirow[t]{5}{*}{ 2. How do you rate your health? } & Very good & 7 & I8 \\
\hline & Good & 44 & 44 \\
\hline & Fair & 30 & 29 \\
\hline & Not good & I2 & 6 \\
\hline & Poor & 6 & o \\
\hline \multirow[t]{2}{*}{ 3. Do you smoke? } & Yes & 7 & 3 \\
\hline & No & $9^{2}$ & 94 \\
\hline $\begin{array}{l}\text { 4. How many days a week do you do a } \\
\text { total of } 30 \text { minutes of physical activity? }\end{array}$ & Mean & $(3 \cdot 5)$ & $(3.8)$ \\
\hline $\begin{array}{l}\text { 5. How many portions of fruit and vegetables } \\
\text { eaten each day? }\end{array}$ & Mean & $(3 \cdot 9)$ & $(4 \cdot 3)$ \\
\hline \multirow{2}{*}{$\begin{array}{l}\text { 6. Have you had a fall in the last } \mathrm{I} 2 \text { months } \\
\text { that required medical attention? }\end{array}$} & Yes & I4 & 3 \\
\hline & No & 87 & 94 \\
\hline \multirow{2}{*}{$\begin{array}{l}\text { 7. In the past two years have you had } \\
\text { an eye test? }\end{array}$} & Yes & 87 & 79 \\
\hline & No & I3 & I8 \\
\hline \multirow[t]{2}{*}{ 8a. Have you had an influenza vaccination? } & Yes & 73 & 68 \\
\hline & No & 25 & 29 \\
\hline \multirow[t]{2}{*}{ 8b. If no, do you usually have a 'flu vaccination? } & Yes & 26 & $2 \mathrm{I}$ \\
\hline & No & I9 & I5 \\
\hline \multirow[t]{2}{*}{ 9. Do you take more than three medications? } & Yes & 57 & $3^{*}$ \\
\hline & No & 37 & 62 \\
\hline \multirow{5}{*}{$\begin{array}{l}\text { Io. Do you believe that generally health is a } \\
\text { matter of luck? }\end{array}$} & Strongly agree & 5 & 9 \\
\hline & Agree & 34 & $2 \mathrm{I}$ \\
\hline & Equivocal $^{3}$ & I9 & 9 \\
\hline & Disagree & 26 & 53 \\
\hline & Strongly disagree & II & 6 \\
\hline $\begin{array}{l}\text { II. Have you recently been happy, all things } \\
\text { considered? }\end{array}$ & Mean score ${ }^{1}$ & (เ.9) & $(2.0)$ \\
\hline $\begin{array}{l}\text { I2. Physical health or emotional problems } \\
\text { interfere with your normal social activities? }\end{array}$ & Mean score ${ }^{2}$ & $(3.0)$ & $(3 \cdot 4)^{+}$ \\
\hline
\end{tabular}

Notes: i. The categories were 'o' much less happy, 'I' less than usual, ' 2 ' same as usual, and ' 3 ' happier than usual. 2. The categories were 'o' extremely, 'I' quite a bit, '2' moderately, ' 3 ' slightly, and ' 4 ' not at all. 3 . Neither agree nor disagree.

Levels of significance: $+p<0 . \mathrm{I}, * p<0.05$.

question whether they took more than three medications $(F=4.65$ (df I, I27), $p<0.05$ ), taken as a good indicator of significant or multiple health problems, probably indicating chronic health problems. The majority $(59 \%)$ of those who persevered to 30 points did not agree with the proposition that health was a matter of luck and believed that their health was in their control, as compared with 37 per cent of those who dropped out, although the difference was not statistically significant $(F=\mathrm{I} .73$ (df I, I04), $p=0 . \mathrm{I} 9)$. This lack of relationship was confirmed by a 
lack of a significant correlation between the number of points gained and agreement with the fatalistic belief.

\section{Regression models of adherence}

The personal responses that differentiated those who persisted from those who dropped out were entered into a stepwise multiple regression analysis to examine which variables predicted adherence, using the achieved number of points as the dependent variable. Age was entered as the first predictor, followed by gender. In the next step, whether or not a person reported an illness and whether or not they were taking more than three medications were entered, together with whether or not they felt their physical or emotional problems had interfered with their social activities during the last four weeks. Finally, their level of agreement with the concept of health being a matter of luck was entered. The model as a whole predicted only a low percentage of the variance $\left(R^{2}=0.07\right)$ in number of points achieved, but the equation was significant $(F=2.3 \mathrm{I}(\mathrm{df} 5, \mathrm{I} 6 \mathrm{I})$, $p<0.05)$. The predictors that had significant effects were age of the participant and whether or not they felt physical or emotional problems had interfered with social activities (both $p<0.05$ ). That the model did not provide a good fit suggests that other variables and barriers that have not been assessed were influential. This was explored by examining variables from the evaluation questionnaire.

The factors affecting how many points a person achieved were regarded as equivalent to the factors affecting adherence and involvement with the scheme. First, there was a significant relationship between the importance of the prizes to the participant and how many points they achieved $(r(60$ cases $)=0.3 \mathrm{I}, p<0.05)$. In addition, those who particularly liked the format also achieved more points $(r(64)=0.28, p<0.05)$. The converse was also true - those who did not like the format achieved fewer points. The number of points achieved was related negatively to the total number of factors ticked that prevented taking part $(r(\mathrm{I} 7)=-0.54, p<$ o.OI), indicating that these items did present significant barriers to taking a full part in the health intervention and that their influence was additive. It is also clear, however, that many of the participants did not experience any barriers. Some of the specific barriers suggested showed particularly strong negative relationships with achieving points, namely 'some of the activities were too difficult', 'I was unclear what to do', transport problems, and mobility problems - all associated with achieving fewer points, $(p<0.05$ in all cases). A further stepwise multiple regression was conducted to examine how these variables, plus age and gender of respondent, together predicted adherence to the programme, again using number of 


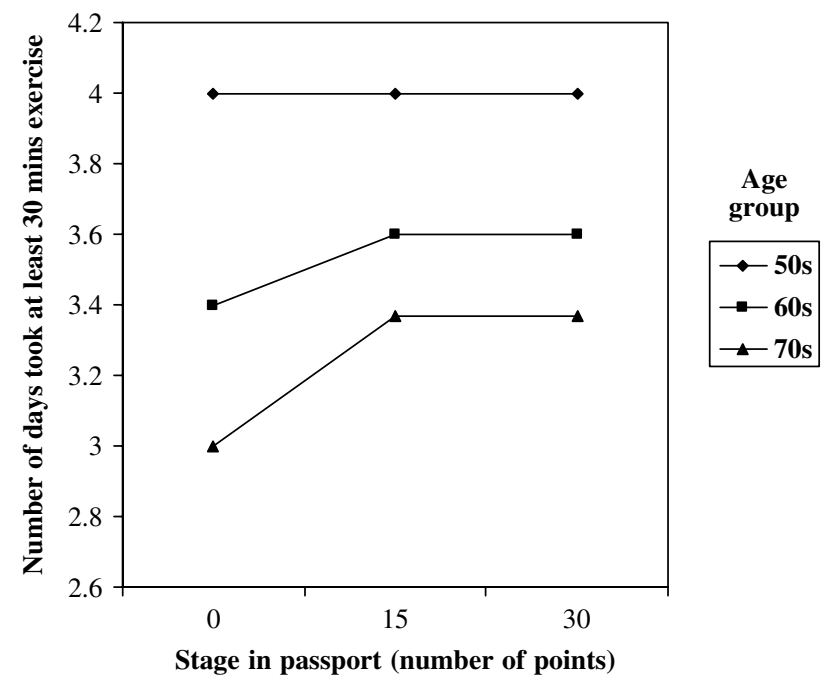

Figure I. Change in number of days people took exercise with increasing number of points in passport.

points achieved as the dependent variable. The model was significant $(F(8,49)=9.69, p<$ o.ooI $)$ and predicted 65 per cent of the variance in points achieved. In descending order of importance to the model, the significant predictors were mobility, being unclear what to do, and importance of prizes. This demonstrated that once these factors were accounted for, age itself did not predict adherence. The large amount of variance accounted for here, as opposed to the first regression model based on the monitoring form data, suggests that the structure of the scheme and the barriers were more important than individual health variables in predicting adherence.

\section{Did people change as a result of the Healthy Passport intervention?}

Beginning with exercise, Figure I shows that the frequency of physical activity was at first low for the older people in the intervention, but by the time they had achieved I5 points had increased significantly $(F=5.35$ (df I, 53), $p<0.05$ ), after which it increased no further. As to diet, the number of portions of fruit and vegetables eaten each day was monitored as participants progressed through the intervention. Figure $2 \mathrm{a}$ suggests that again older people changed between o and 15 points, particularly those aged in their sixties. As only one person aged $5^{-}-59$ years and no one aged over 80 years completed all the requisite sections at all three stages, analysis was conducted on all those who completed i5 points. As can be seen in Figure 2b, people aged in their fifties and sixties increased their 


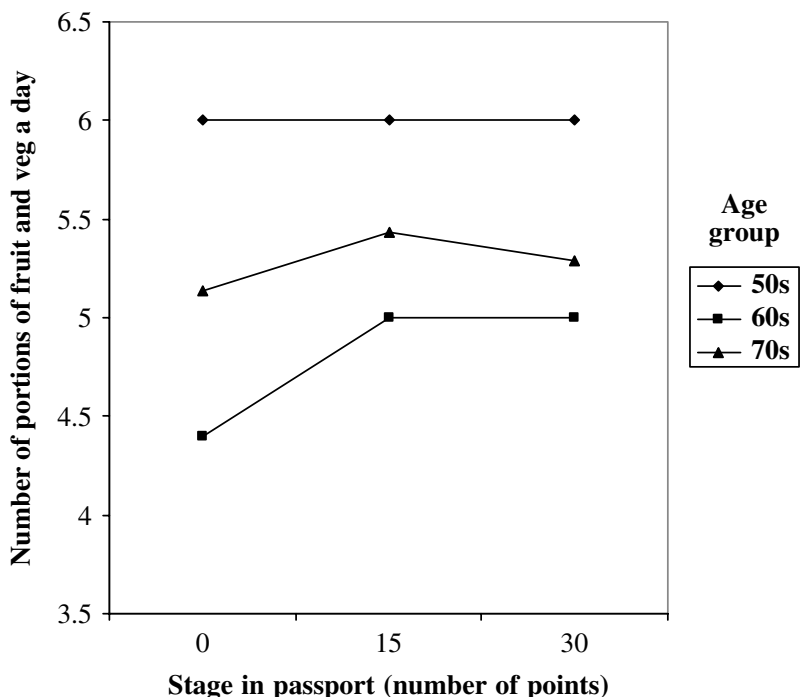

Figure 2a. Number of portions of fruit and vegetables consumed a day, by age.

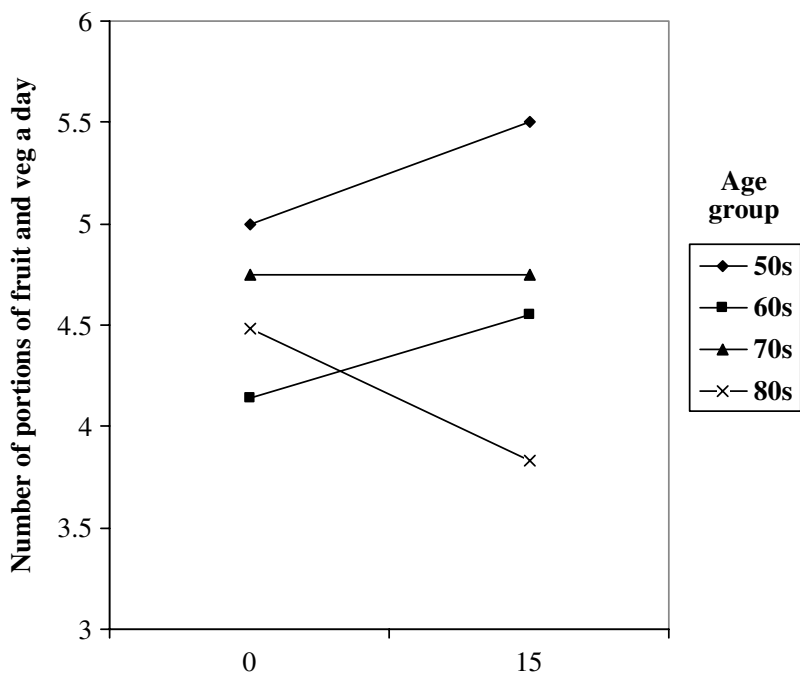

Stage in passport (number of points)

Figure $2 \mathrm{~b}$. Change in number of portions of fruit and vegetables between o and $\mathrm{I} 5$ points.

consumption, but those aged in the seventies showed no change and those over 80 seemed to reduce consumption. The statistical analysis confirmed this unexpected result: the interaction between age and accumulated points stage was statistically significant $(F=5.6 \mathrm{I}(\mathrm{df} 3,44), p<0.0 \mathrm{I})$. 


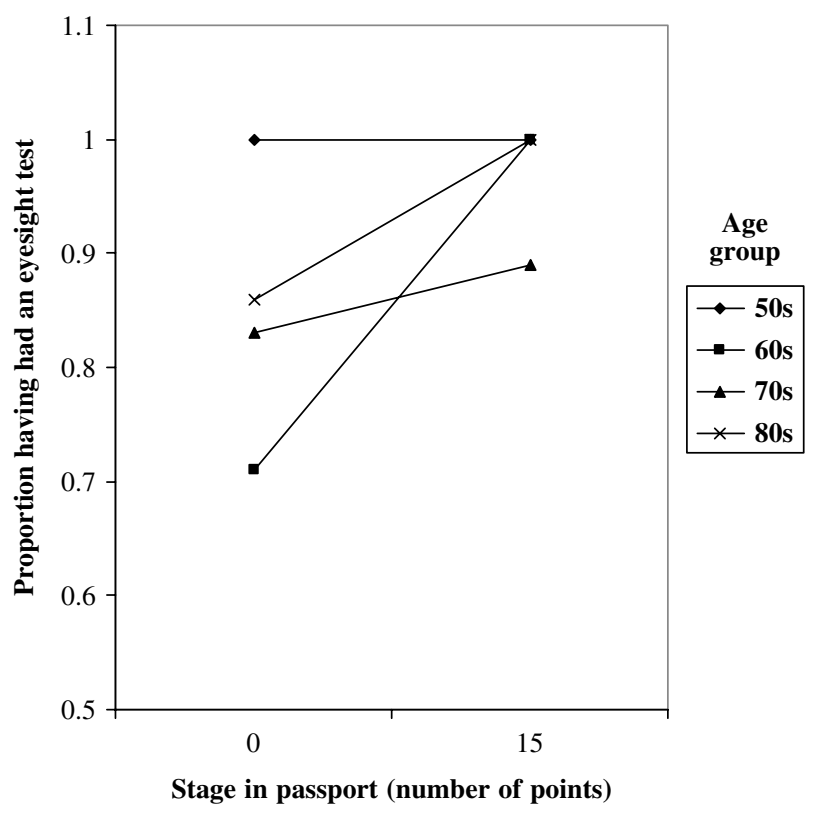

Figure 3. Change in proportion of people having had an eyesight test between o and I5 points, by age group.

Turning to the uptake of an influenza vaccination, amongst the older age group, who are routinely invited to receive a free vaccination by the NHS, uptake was already very high but was raised further by the programme. Repeated-measures analysis of variance revealed an effect of stage: more people had taken up the vaccination by $\mathrm{I} 5$ points $\left(F=4 . \mathrm{II}\left(\mathrm{df} \mathrm{I}, 5^{\mathrm{I}}\right.\right.$ ), $p<0.05)$. By the 15 points stage, every person aged 70 or more years still in the programme had received the "flu vaccination. On self perception of health, there was no overall effect across the three stages, but a marginally significant improvement between o and I5 points $(F=3.36$ (df I, 55), $p=0.07)$. As for change in tobacco smoking, only eight participants smoked, and one of the five still in the scheme after the first stage gave up smoking. The uptake of eyesight tests, which are provided free-of-charge by the NHS for the over-6os, was already high. Figure 3 illustrates a small increase in uptake between o and 15 points for those in their sixties and eighties. This effect was significant only for those in their sixties, for whom initial uptake was the lowest $\left(t=-2.5^{\mathrm{I}}, p<0.05, \mathrm{~N}=20\right)$.

On the incidence of falls, evidence from the general population is that in any given year, one-in-three people aged 65 or more years experience a fall (Simoneau and Liebowitz 1996). Among the study sample, when initial monitoring forms were completed, I 4.5 per cent had fallen during the 
previous I 2 months and later, I7.5 per cent had fallen at I5 points, and I 3 per cent at 30 points. The figures suggest that the group had a low frequency of falls, and that the programme had no effect. On the belief that health is a matter of 'luck', this did not change with progress through the Passport, although, as is usual, an increase in this belief with increasing age was found $(r=0 . \mathrm{I} 8, p<0.05, \mathrm{~N}=\mathrm{I} 8 \mathrm{I})$. Self-rated recent happiness, all things considered did not change significantly over the course of the programme. Agreement with the statement that physical health or emotional problems interfered with social activities during the previous four weeks slightly decreased among those aged 60 or more years between o and 15 points but the effect was not statistically significant.

\section{Reported lifestyle changes}

On average, all age groups reported that they had made changes to their life styles as a result of the Healthy Passport scheme, but the percentage was relatively low among those aged in their late seventies (not statistically significant). ${ }^{8}$ It was expected that the oldest participants would be least likely to show change, but the over-eighties were comparatively likely to have made changes. The participants also filled in an open section on the evaluation questionnaire saying what they thought had changed. The majority of those responding said they had adopted more healthy eating $(39 \%)$ or more walking or exercise $(33 \%)$, although people also indicated other positive aspects such as 'met new people' and 'encouraged each other', or had become more active and joined classes and groups not associated with the Passport.

\section{What predicted change?}

Factors affecting change were explored in a series of correlation analyses. First, the relationship between reporting that they had made changes as a result of taking part, and achieving more points, was not statistically significant. However, reporting that they had changed was related to how important the incentives were to the individual $(r(54)=0.3 \mathrm{I}, p<0.05)$, and to how much a person had enjoyed taking part $\left(r\left(5^{6}\right)=0.35, p<\right.$ o.o $)$. Achieving change was negatively related to feeling that they had been prevented from achieving more points because of being too busy, or feeling unclear about what to do (both $p<0.05$ ) - that is, these barriers significantly reduced the likelihood that changes would be experienced.

The finding that people who enjoyed the experience were more likely to make positive changes was examined by exploring the factors that predicted enjoyment of the programme. The number of points achieved and importance of the incentives were not significantly related to how 
T А в L E 4. Modal responses and percentage finding explanations easy to understand by age group

\begin{tabular}{|c|c|c|c|c|}
\hline \multirow{2}{*}{$\begin{array}{l}\text { Age } \\
\text { group } \\
\text { (years) }\end{array}$} & \multicolumn{2}{|c|}{$\begin{array}{l}\text { Understanding of } \\
\text { explanation of activities }\end{array}$} & \multicolumn{2}{|c|}{$\begin{array}{l}\text { Understanding of the } \\
\text { Healthy Passport scheme }\end{array}$} \\
\hline & Modal response & $\begin{array}{c}\text { Easy to } \\
\text { understand }\end{array}$ & Modal response & $\begin{array}{l}\text { Easy to } \\
\text { understand }\end{array}$ \\
\hline $55-59$ & Just right & $33 \%$ & Easy to understand & $66 \%$ \\
\hline $6 o-64$ & Just right & $25 \%$ & Just right & $38 \%$ \\
\hline $65^{-69}$ & Just right & $42 \%$ & Easy to understand & $58 \%$ \\
\hline $70-74$ & Easy to understand & $67 \%$ & Easy to understand & $66 \%$ \\
\hline $75-79$ & Easy to understand & $43 \%$ & Just right & $36 \%$ \\
\hline $80-84$ & Easy to understand & $33 \%$ & Just right & $33 \%$ \\
\hline $85^{-89}$ & Difficult to understand & $0 \%$ & Just right & $0 \%$ \\
\hline
\end{tabular}

much people enjoyed it, but liking the format related to enjoyment, as did finding enough variety of activities, and having easy-to-understand explanations of the activities (all $p<0.05$ ). In addition, those who enjoyed the passport were also were more likely to report that they had received support from the older people's champions. This was a highly significant effect $\left(r\left(5^{8}\right)=0.48, p<\right.$ o.ooI $)$ underlining the importance of the role. As these are correlation analyses, it must be pointed out that the converse of these relationships is also true: not liking the format, finding enough activities, not understanding the explanations or receiving support had a deleterious effect on enjoyment, and so on the changes that were likely to be made.

\section{The participants' evaluations of the scheme}

The evaluation forms showed that bicycling was disliked, but all the other physical activities were popular (in rank order, the extend class, healthwalk and green-gym). Other aspects of the intervention were reported as more useful and enjoyable, however, with healthy eating, health assessment, the 'flu and pneumonia vaccinations, and eyesight and medication checks being very popular.

\section{Did participants find the Passport and explanations of activities easy to understand?}

No participants reported the overall scheme difficult to understand, and there were no significant differences between age groups (see Table 4), but it was clear that people aged $70^{-} 74$ years reported the readiest understanding of the individual activities $(F(\mathrm{df} 6,52)=2.88, p<0.05)$. The one respondent aged $85^{-89}$ years found the explanations difficult to 
understand, in line with comments from the champions on difficulties experienced by this age group (of which more below). The Black British and Caribbean participants were significantly less likely to report that the Passport, or the individual activities, were easy to understand than the White British (both $p<0.05$ ).

\section{Would they do it again?}

Of the $5^{6}$ people who completed this question on the evaluation forms, $9^{6}$ per cent would have participated again. This was positively related to how much they had enjoyed it $(p<0.05)$, strongly related to how many points they had achieved $(p<0.00 \mathrm{~s})$, finding it relatively easy to achieve the points $(p<0.05)$ and being quite keen on the incentives $(p<0.05)$. Being willing to do it again was affected negatively by being unclear about what they were supposed to do, by transport difficulties and by the number of reported barriers (all $p<$ o.oI).

\section{The views of the older people's champions}

The views of the older people's champions were elicited in two ways: first, by way of a group workshop with the managers of the scheme, and secondly, through telephone interviews by the independent evaluators after the end of the scheme. The general themes elicited included negative and positive issues, although overall they were extremely positive about the role and the scheme. The negative themes were the difficulties in arranging transport, the poor understanding of the activities or the forms (especially among the over-8os), and older people's reluctance to have home visits or to go to their GPs for the medical checks. They reported unease and misunderstandings amongst the oldest people with health assessments. The champions recommended more piloting of explanations and wordings.

Their main positive themes were the reduction of isolation and that when activities were in groups, there was greater enthusiasm and competition. They found recruiting 65 to 75 year-olds easiest, as most younger people had work commitments. They found the majority of participants to be very positive, specifically commenting on the social rather than healthrelated aspects of the scheme. As one male champion, aged 64 years, who was a retired industrial manager said: 'the Healthy Passport gave them a purpose and an opportunity to meet those similar to themselves. They were able to make new friends and take part in group activities'. The champions believed that the passport was having a long-term effect in their communities, citing evidence of groups of the participants continuing to go for walks and taking part in other leisure activities together. 
The champions were very clear that being near the same age as the participants was essential to the success of their role. At least one champion was doing the passport herself. This lady, aged 73 years, who was a retired export manager made the following comments:

[Our shared age] makes it much easier to relate to them. That was what makes the whole thing work - being able to relate to them. ... The Passport worked very well for the older people as it gave them a purpose and showed them that even once they are retired they can still lead a full, healthy and active life. It also showed them that they were able to enjoy the social side of life.

\section{Discussion}

The Healthy Passport intervention aimed to encourage people aged $5^{\circ}$ or more years enjoy a happier and healthier lifestyle. The evaluation set out to determine the success in terms of several criteria, as described, and specifically to evaluate the roles of incentives and peer-group supporters. The majority of participants were between 60 and 84 years old, with younger groups being under represented. This is as expected, given that many younger older people are still in work and would not have been aware of the scheme. It is also a reflection of membership of the clubs and societies at which the majority were recruited. Nevertheless, people in their fifties are unlikely to see an intervention they perceive as aimed at older people to be relevant to them - they are unlikely to think of themselves as 'old'.

Previous research has shown, however, that this age group is one that is often highly concerned by the onset of health problems, or age-related changes such as declining memory (Rabbitt and Abson 1990), and are also more likely to believe that they have some control over their health (e.g. Girasek 200I). Indeed, Deery et al. (2000) suggested that encouraging changes in late middle age/early older age may be more successful than targeting apparently more needy older groups, perhaps at least partially as a result of these beliefs. The pertinent results reflect these previous findings: the increase in belief in health as a matter of luck with increasing age found here supports Girasek's findings, and the findings on the little dietary change by the oldest participants confirmed Deery and colleagues' concerns about targeting the oldest age groups. However, the oldest people in the evaluation questionnaire responses were no less likely to report having made changes than younger groups. This finding is almost certainly an effect of selective attrition, the few octogenarians being likely to be more healthy, active and committed to the intervention than the many of this age who dropped out at an earlier stage, who may be presumed to be less likely to have shown changes as a result of 
their contact with the passport. Nevertheless, aiming health interventions at people aged in their fifties would be expected to be highly successful and future research should explore ways of specifically targeting this group.

In contrast to the low uptake by those of Asian origin, the proportion of the participants of Afro-Caribbean ethnicity was higher than their representation in the local population. There is evidence that older people in this group have poorer health than their white peers, e.g. higher rates of stroke and diabetes, and of obesity in women (Department of Health 2000), and the uptake and very positive adherence of this group shows that such initiatives were welcomed by them. It should be borne in mind, however, that the number in this group was small.

\section{Who carried on?}

There was clear evidence of selective attrition in that those who carried on to 30 points were younger, and on some measures healthier than the average registrant, although those who achieved 15 points differed little from the original cohort. The 15 points threshold was important for most of the significant changes, such as having an eyesight test, exercising more frequently, and eating more fruit and vegetables, occurred between o and I5 points. The selective attrition may therefore not have had as significant consequence as one may expect from the loss of the older participants at a later stage - those who only acquired I5 points did achieve significant changes. The health and safety interventions literature recommends refreshing the activities, e.g. adding new ones or using progressive personal pledges or 'implementation intentions' to encourage long-term adherence (e.g. Sheeran and Silverman 2003). More research is needed to examine whether such adaptations enhance changed behaviour among participants rather than just maintain them, as in this study. The older the participant and the more that they believed that their health and emotional problems interfered with social activities, then the fewer points they achieved; that is, they were less involved. The older people's champions' very positive appraisal of the benefits of the programme's opportunities for social engagement implies that if this aspect was not easily accessible, then engagement in other aspects of the programme was affected. The data on specific barriers suggest that transport and mobility issues had a highly significant influence on participation.

\section{Did people change?}

Any health promotion intervention needs to be evaluated on the criterion of value for money, which is a function of participation, changes 
in health-related behaviour, increased social activities and involvement, and wellbeing and health outcomes. The passport scheme increased the number of days that the participants aged in their sixties and seventies did at least 30 minutes of physical activity, and raised the number of portions of fruit and vegetables eaten each day by people aged in their fifties and sixties (but not the older age group). Evidence from dietary intervention research suggests that older people are well able to absorb information about the benefits of fruit and vegetables and dietary improvements if given well-designed and tailored information, but that much contemporary dietary advice confuses them. The distinction underlines the need for specific support for different groups of people.

One very clear success was in the take-up of the vaccinations and other health-care opportunities. Although many of the participants had been vaccinated for influenza before they registered with the Healthy Passport, the intervention achieved Ioo per cent take-up among those aged 70 or more years. The take-up of eyesight tests was greatest amongst those who were least likely to have had an eyesight test within the previous two years (those aged in their sixties) - another considerable success for the scheme. More generally, although the participants felt marginally better as they progressed through the scheme, the feeling that their ailments interfered with social activities did not change.

\section{Predicting adherence and change}

There were two threads in the relationships between participation in the Passport and the outcomes. One was the factors that predicted how long a person would stay in the project and their level of involvement (i.e. the number of points they achieved), and the other was the factors that predicted change. The incentives and barriers related to both, but a high points total was not a prerequisite of change. Enjoyment of the Passport did seem to be necessary for change, while support from the peer group organisers, the level of understanding and reactions to the explanations and format all related to this thread. The regression analyses showed that barriers such as mobility and (poor) understanding were more important predictors of adherence than age itself. It is surmised that previous evidence of poor take-up amongst the oldest age groups may be explained by accessibility effects rather than a true age effect. The difference in the predictive ability of the two regression models clearly demonstrated that 'structural' characteristics, such as the personal importance of the incentives and likes and dislikes of the format, had a greater impact on the level of involvement than background attributes such as age or health, although direct comparison of the two groups of characteristics was not 
possible. The analysis has demonstrated that the individual's evaluation of the incentives is a strong influence, which contrasts with previous evaluations that have examined only the presence or absence of incentives. This finding adds weight to the conclusion that pilot tests of the acceptability of the particular incentives with the target population is most important. The success of the intervention can also be measured in terms of whether people are willing to take part in an extended or related intervention to improve their health, reduce isolation and improve social engagement; the answer was almost unanimously 'yes' (96\%).

\section{Limitations of the evaluation}

A major drawback for the interpretation of the findings is that a limited number of participants completed the monitoring questionnaires at the later stages. The analysis has consequently probably missed some important significant differences. Some analyses could not be conducted on those who accumulated 30 points because of empty cells for some age groups and insufficient valid answers. A related issue is that those who filled in the evaluation questionnaire had achieved a significantly greater number of points than the average registrant. Those who achieved fewer points or dropped out earlier may have experienced more difficulties or had other opinions about the passport. On the other hand, the respondents were more likely to be in a position to pass comment on the wide range of the Passport's activities, simply because they did more of them. A further limitation is the difficulty that some people, especially the oldest participants, had with filling in the forms. The champions all mentioned this and reported that many forms were only completed with concerted support from the champions. Nevertheless, it is still possible that some respondents may have misunderstood some questions, which again is an argument for the need for extensive piloting of evaluation instruments with all age and ethnic groups.

\section{Suggestions for future interventions with older adults}

Whelton et al. (1998) noted that adherence to exercise and healthy-eating trials can be developed through providing social reinforcement and instructional sessions with the participants. Salient features of the Passport were the influence of enjoyment of its sociable aspects, as emphasised by the older people's champions, and that reducing isolation and bringing people into contact with one another through the intervention provided mutual encouragement (and competition). This effect was seen as very valuable and something that could be further improved. Whelton et al. (1998) also suggested that maintaining adherence can be positively affected 
when the intervention co-ordinators provide feedback and reinforcement (elements not present in the Passport scheme). This suggests that the monitoring stages could be elaborated, and ways of providing more feedback and encouragement at these stages should be explored. It may be that more feedback would have challenged the belief that 'health is a matter of luck', the level of which did not change.

The difficulties some of the oldest participants seem to have had with the questionnaires, as noted by the champions, and the low adherence of people for whom English was not their first language, suggests that alternative feedback and evaluation methods should be explored, such as group or individual interview techniques. In addition, the champions' reflections on the benefits of being the same age and being able to relate to the participants strongly supports their role, but may also explain why some ethnic groups were under represented. Appointing peer advisors or older people's champions from all the major ethnic groups in a local population may improve take up (e.g. Taylor, Serrano and Anderson 200I).

Although it has been shown that the incentives promoted the success of the scheme, not all the participants regarded them as important. The same could be said of the activities. Not all the offered activities attracted all the participants. The provided activities need to be selected carefully and subjected to pilot evaluations to suit the diversity of the population. More generally, the healthy behaviour interventions literature strongly supports thorough piloting with the target population to ascertain their particular beliefs and influences. For example, work on pedestrian safety behaviour amongst this older age group by Holland and Hill (2007) demonstrated clearly that different predictors of target behaviour are important for different age and social groups. For example, targeting attitudes and perceived outcomes was shown to be important for the oldest groups and subjective norms (peer-group influences) less so. In addition, perceived vulnerability, or the perceived risk of negative consequences (e.g. of catching influenza) has an impact on health-related behaviour. Thus, determining people's perception of vulnerability is an important step in piloting health promotion interventions. Previous research has suggested that perceived behavioural control (related to self efficacy, or belief in one's own ability to perform a behaviour) may be particularly important in predicting the behaviour of older people (e.g. Holland and Hill 2007). This study has found that some activities rated as too difficult were negatively associated with adherence and successful outcomes. Ways of overcoming such barriers need to be explored, both in the design of the activities and their explanations, particularly to maximise their suitability for the less physically fit. Consideration should also be given to offering personal mastery training or peer models of behaviour. 


\section{Conclusions}

In conclusion, the Healthy Passport was a beneficial programme and led to many participants changing their behaviour, especially with reference to diet, exercise changes and the take-up of influenza vaccinations. Although the oldest people were most likely to drop out at a relatively early stage, many of the significant positive changes occurred before their participation ceased. The key feature to promote adherence, the incentive scheme, associated with achieving points and behaviour change. On the other hand, the points achieved did not associate with reports of behaviour change - this was more a function of enjoyment of the scheme. The role of the older people's champions was strongly confirmed in terms of significant associations of the presence of their support with enjoyment and so successful change. The regressions showed that barriers to involvement and the personal rating of the incentives were better predictors of involvement than age itself, leading to the conclusion that carefully planned structural components of interventions can overcome age and health-related issues of involvement and attrition. Finally, the differential rates of take-up by age and ethnic groups suggest that a single Passport scheme and associated activities may not be appropriate for all, and that cultural diversity needs to be taken into account in planning and piloting such initiatives.

\section{Acknowledgments}

Healthy Passport was managed by Agewell, in conjunction with Wednesbury and West Bromwich Primary Care NHS Trust (now Sandwell NHS PCT), and the Greets Green Partnership. This project was funded by Sandwell Borough's Neighbourhood Renewal Fund along with West Bromwich Town Team, Wednesbury Town Team and Greets Green Partnership (Healthier and Safer Older Age Project). The views expressed in this document are those of the authors and are not necessarily those of Agewell, the Primary Care NHS Trusts or associated bodies.

\section{NOTES}

I The principal town in Sandwell is West Bromwich, which lies about Io kilometres WNW of the City of Birmingham, the commercial heart of the West Midlands. The area is part of the 'Black Country' that prospered in the igth century through specialist metal manufacture (notably springs), heavy engineering and the chemical industry.

272.5 years for men, 78.7 years for women, as compared with the national average of 75.2 and 8o.I respectively, 200I data national. 
3 Agewell is an organisation funded primarily by the UK National Health Service and its local Primary Health Care Trust (PCT). For specific initiatives it also receives funding from the Government Neighbourhood Renewal Fund (NRF), and from the borough or individual towns. It organises a variety of activities that emphasie enabling older people to have a voice in their community. Further details can be found at http://www.agewellinsandwell.org.uk

4 The booklet was attractively designed by a company chosen for its experience and understanding of the target group. The planning group, including the Older People's Champions, assessed its usability.

5 These incentives were chosen based on consultation with a planning group which included the Older People's Champions. The non-slip slippers were selected as a reinforcing falls-prevention intervention.

6 Both the monitoring and the evaluation questionnaires were designed by one of the authors, a community development specialist, in conjunction with a public-health researcher. They were assessed by funders, planners and the 'Agewell' team, and piloted with the older people's champions.

7 The average age of the men was 7I.5 years, and of the women 70.I years. Two participants did not answer the gender question.

8 The number and percentages that reported change by age $55^{-59}, 60-64,65-69$, $70-74,75-79$ and $80+$ years were as follows: $3(66 \%), 7(63 \%)$, i $7(74 \%)$, I I $(53 \%)$, II $(36 \%)$ and $6(57 \%)$.

\section{References}

Age Concern England 2007. Ageing Well Programme. Age Concern England, London. Available online at http://www.ageconcern.org.uk/ [Accessed 22 May 2007].

Akke, K. van der B., Laurant, M. G. H. and Wensing, M. 2002. Effectiveness of physical activity interventions for older adults. American Fournal of Preventive Medicine, 22, 2, 120-33.

Anderson, R. T., Ory, M., Cohen, S. and McBride, J. S. 200o. Issues of aging and adherence to health interventions. Controlled Clinical Trials, 21, ${ }_{17 \mathrm{IS}-183} \mathrm{~S}$.

Department of Health 2000. I999 Health Survey for England. Department of Health, London.

Department of Health 2004. Choosing Health: Making Healthy Choices Easier. White Paper Cm 6374, Stationery Office, London.

Department of Health 2006. Tackling Health Inequalities: 2003-2005. Update for the National 2010 PSA Target. Department of Health, London.

Deery, H. A., Day, L. M. and Fildes, B. 2000. An impact evaluation of a falls prevention program among older people. Accident Analysis and Prevention, 32, 3, 427-33.

Girasek, D. C. 20or. Public beliefs about the preventability of unintentional injury deaths. Accident Analysis and Prevention, 33, 4, 455-65.

Giuffrida, A. and Torgerson, D. J. I997. Should we pay the patient? Review of financial incentives to enhance patient compliance. British Medical fournal, $3 \mathbf{I} 5$ (20 September), 703-7.

Holland, C. A. and Hill, R. 2007. The effect of age, gender and driver status on pedestrians' intentions to cross the road in risky situations. Accident Analysis and Prevention, 39, 2, $224-37$.

Kavanagh, J., Trouton A., Oakley, A. and Powell, C. 2006. A Systematic Review of the Evidence for Incentive Schemes to Encourage Positive Health and Other Social Behaviours in Young People. EPPI-Centre, Social Science Research Unit, Institute of Education, University of London, London.

Kellogg, S. H., Burns, M., Coleman, P., Stitzer, M., Wale, J. B. and Kreek, M. J. 2005. Something of value: the introduction of contingency management intervention into the 
New York City Health and Hospital Addiction Treatment Service. Fournal of Substance Abuse Treatment, 28, I, 57-65.

Kocken, P. L. and Voorham, A. J. J. 1998. Interest in participation in a peer-led senior health education program. Patient Education and Counseling, 34, I, 5-I4.

Lynde, B. D. 1992. Nutrition promotion for mature adults: a case study in peer education. Journal of Nutrition in the Elderly, $\mathbf{I} \mathbf{1}, 3$, 19-31.

Maddox, G. L. I985. Intervention strategies to enhance well-being in later life: the status and prospect of guided change. Health Services Research, I 9, 6 (part 2), I007-32.

National Statistics 2005. Age-range 200I. 200I population census statistics, National Statistics, London. Available online at http://www.statistics.gov.uk/census20or/ pyramids/pages/ooCS.asp [Accessed 20 March 2007].

National Statistics 2005. West Midlands: Ethnic Group of Residents. 200I population census statistics, National Statistics, London. Available online at http://www.statistics.gov.uk/ StatBase/xsdataset.asp ?vlnk $=\mathrm{I} 665 \&$ More $=\mathrm{Y}$ [Accessed 20 March 2007].

Pereira, M. A., Kriska, A. M., Day, R. D., Cauley, J. A., LaPorte, R. E. and Kuller, L. H. I998. A randomised walking trial in postmenopausal women: effects of physical activity and health io years later. Archives of Internal Medicine, r 58, I5, I695-70 .

Petry, N. M. and Bohn, M. J. 2003. Fishbowls and candy bars: using low cost incentives to increase treatment retention. NIDA Science and Practice Perspectives, 2, I, 55-6I.

Rabbitt, P. and Abson, V. I99o. Lost and found: some logical and methodological limitations to self-report questionnaires as tools to study cognitive ageing. British fournal of Psychology, 8I, I, I-I6.

Rabbitt, P., Diggle, P., Holland, F. and McInnes, L. 2004. Practice and drop-out effects during a i7-year longitudinal study of cognitive aging. Fournal of Gerontology: Psychological Sciences, 59B, 2, $\mathrm{P}_{4}-97$.

Research Sandwell 2007. Age and Sex by Ethnic Group. Table Sior, Local Population Statistics. Research Sandwell, Sandwell, West Midlands. Available online at http://www. researchsandwell.org.uk/ [Accessed 29 May 2007].

Simoneau, G. G. and Leibowitz, H. W. I996. Posture, gait and falls. In Birren, J. E. and Schaie, K. W. (eds), Handbook of the Psychology of Aging. Fourth edition, Academic, San Diego, California, 204-35.

Sheeran, P. and Silverman, M. 2003. Evaluation of three interventions to promote workplace health and safety: evidence for the utility of implementation intentions. Social Science and Medicine, 56, 10, 2153-63.

Taylor, T., Serrano, E., and Anderson, J. 200I. Management issues related to effectively implementing a nutrition education program using peer educators. Fournal of Nutrition Education and Behavior, 33, 5, 284-92.

Whelton, P. K., Appel, L. J., Espeland, M. A., Applegate, W. B., Ettinger, W. H. Jr, Kostis, J. B., Kumanyika, S., Lacy, C. R., Johnson, K. C., Folmar, S. and Cutler, J. A. I998. Sodium reduction and weight loss in the treatment of hypertension in older persons: a randomized controlled trial of nonpharmacologic interventions in the elderly (TONE). Fournal of the American Medical Association, 279, II, 839-46.

Accepted I9 October 2007

Address for correspondence:

Carol Holland, Psychology, School of Life and Health Sciences, Aston University, Birmingham $\mathrm{B}_{4} 7 \mathrm{ET}$, UK.

E-mail: c.hollandi@aston.ac.uk 